SOBRE O RACIOCÍNIO MORAL

ABOUT MORAL REASONING

Eugênia Ribeiro Teles ${ }^{1}$

Recebido em: 07/2018

Aprovado em: 10/2018

Resumo: O objetivo deste artigo é elucidar alguns conceitos e elementos relacionados ao raciocínio moral. ${ }^{2}$ Para tanto, iniciaremos clarificando o que chamamos de raciocínio em geral, como ele pode ser classificado e qual sua relação com as razões que embasam nossas ações. Uma vez feito isso, procuraremos mostrar como o raciocínio moral pode ser compreendido, qual a sua relação com os princípios morais, quais componentes mentais podem fazer parte nesse tipo de raciocínio e, por fim, quais os possíveis resultados decorrentes desse processo deliberativo.

Palavras-chave: Raciocínio. Raciocínio Moral. Emoções. Princípios Morais. Ação.

\begin{abstract}
The purpose of this paper is to elucidate some concepts and elements related to moral reasoning. To do so, we first clarify the general concept of reasoning, how it can be classified and its relation to the reasons underlying our actions. Once that has been completed, we will try to show how moral reasoning can be understood, how it relates to moral principles, what mental components can be involved in this type of reasoning, and finally, what possible outcomes are derived from this deliberative process.
\end{abstract}

Keywords: Reasoning. Moral Reasoning. Emotions. Moral Principles. Action.

\title{
Introdução
}

Frequentemente, em diversas situações nas nossas vidas, nós temos que pensar e decidir o que fazer. Quando as questões que envolvem decisões são sobre o que devemos moralmente fazer ou não, ou sobre o que é moralmente certo ou errado, estamos diante de questões morais, as quais demandam decisões que podem estar diretamente relacionadas com as nossas ações. Esse tipo de decisão, envolvida nas questões morais, geralmente é encontrada através do que chamamos raciocínio moral.

\footnotetext{
${ }^{1}$ Doutora em Filosofia pela Universidade Federal da Paraíba.

${ }^{2}$ Recorte da Tese "Sobre a determinação das emoções na resolução dos dilemas morais", defendida junto ao Programa Integrado de Pós-Graduação em Filosofia - PIPGF/UFPBUFPE-UFRN sob a orientação do prof. Dr. Marconi Pequeno com fomento da CAPES.
} 
Questões do tipo: devemos "furar" a fila de um banco passando na frente dos outros que estão esperando? Devemos praticar um aborto, justificando que o corpo nos pertence e que devemos decidir se matamos o feto ou o deixamos viver? É certo nos apropriamos dos animais, mantê-los em condições precárias e violentas com a finalidade de satisfazer o nosso paladar? É sempre errado mentir? Ou existem situações em que a mentira é permitida? Existe uma infinidade de perguntas como essas relacionadas com as nossas ações. Assim, em busca de respostas, nós raciocinamos sobre o que devemos ou não fazer. Nesse sentido, muitos elementos podem participar desse processo de decisão. Então, quais elementos são esses? De que modo deliberamos moralmente? E, finalmente, qual o resultado do nosso raciocínio moral: será uma ação, ou uma intenção de ação?

A partir dessas inquirições, neste trabalho, tentaremos elucidar alguns conceitos e elementos relacionados ao raciocínio moral. Assim, começaremos por tentar clarificar o conceito geral de raciocínio. Feito isso, procuraremos ilustrar o que significa o raciocínio moral, pontuando em primeiro lugar, qual a relação desse tipo de raciocínio com os princípios morais, em seguida, consideramos alguns componentes mentais que podem fazer parte desse tipo de raciocínio e, por fim, sugerimos um possível resultado atrelado à deliberação moral.

\section{O que é o raciocínio?}

Nós, seres humanos, somos dotados da capacidade de refletir, questionar, intuir, inferir proposições a partir de outras, predizer acontecimentos futuros com base em acontecimentos passados, entre outras. O raciocínio é uma dessas capacidades que nos permite adquirir novos conhecimentos a partir do que já sabemos ou aprendemos, nos possibilitando um encadeamento de informações, seja através de experiências, ou, seja através de abstrações. A atividade de raciocinar está ligada ao uso da razão na busca do entendimento e compreensão das coisas, envolvendo ainda a associação de ideias ou a correlação de juízos que justificam ou validam as conclusões a que chegamos. Assim, partimos de certas informações ou questões e chegamos a determinadas conclusões, avaliações, decisões ou novas informações a respeito do que raciocinamos. Tradicionalmente, o termo 'raciocínio' está relacionado ao raciocínio lógico formal envolvido nos argumentos dedutivos (Haidt, 2000). Também, de acordo com o Dicionário de Filosofia Armand Colin "o raciocínio é o encadeamento de enunciados de acordo com ligações necessárias e segundo as regras lógicas. Operação consistente que visa estabelecer a verdade ou a falsidade de uma conclusão a partir das premissas (...)" (BARAQUIN, 
BAUDART, DUGUÉ, LAFFITTE, RIBES e WILFERT, 2011, p.428).

Do ponto de vista filosófico, o raciocínio correto está associado à lógica (Shapiro, 2013). Porém, de que forma se dá essa relação? Desde a reviravolta linguística (linguistic turn) operada por Frege e Russell, a filosofia analítica tem recorrido à análise lógica como forma de traduzir os enunciados da linguagem natural para uma linguagem lógica. Foi a análise lógica presente na teoria das descrições definidas apresentada no artigo Da Denotação, em 1905, que introduziu um método filosófico através de uma rigorosa análise de proposições problemáticas usando como ferramenta a lógica de primeira ordem desenvolvida por Frege. Russell acreditava que era possível, através da lógica, ser capaz de explicitar a forma lógica de proposições da linguagem natural. Assim, a análise lógica de uma proposição poderia ajudar a resolver vários problemas de referência associados a ambiguidades e imprecisões da linguagem natural.

Com efeito, muitas vezes o significado de certos termos utilizados na linguagem natural é ambíguo. Por exemplo, analisemos as duas sentenças: "as maçãs são verdes" e "os dias da semana são sete”. Nas duas sentenças temos o uso do verbo “ser”, porém, será que esse verbo tem o mesmo significado em ambas? Na primeira frase queremos dizer que as maçãs possuem a propriedade verde. Traduzindo a sentença para uma linguagem formal, temos: $\forall \mathrm{x}(\mathrm{M}(\mathrm{x})$ $\rightarrow \mathrm{V}(\mathrm{x})$ ). Já na segunda sentença, estamos querendo dizer que o número de dias da semana é igual a sete, ou seja, $\forall \mathrm{x}(\mathrm{N}(\mathrm{x}) \rightarrow \mathrm{x}=\mathrm{a})$, onde $\mathrm{N}=$ número dos dias da semana e a=7. Logo, percebemos o duplo significado do verbo ser que, dentre outros usos, pode ser usado no sentido de qualificar e no sentido de igualdade.

Além da análise lógica nos permitir representar a forma das sentenças da linguagem natural, ela nos permite representar também a forma dos raciocínios. As formas lógicas mais básicas dos raciocínios são aquelas que resultam da aplicação de uma regra de inferência. Uma ilustração dessa aplicação de regras é dada aqui pelo uso de uma regra lógica bem conhecida chamada Modus Ponens, cujo significado é, se P implica Q, e P é o caso, então podemos concluir Q. Assim, por exemplo,

Se chove, então há nuvens (se P então Q)

Chove (P)

Portanto, há nuvens $(\mathrm{Q})$

Nesse exemplo, temos duas premissas que são verdadeiras e temos uma conclusão também verdadeira que foi deduzida a partir das premissas. Isso leva a uma questão concernente 
à relevância filosófica dos vários aspectos matemáticos da lógica, qual seja: como a dedutibilidade e a validade estão relacionadas com o raciocínio correto? Como as relações matemáticas podem ser aplicadas a realidades não matemáticas? (Shapiro, 2013). Ou ainda, como uma linguagem formal matemática pode capturar ou bem traduzir uma linguagem natural?

De acordo com Shapiro (2013), de um lado existe uma visão de que as linguagens formais exibem com precisão características reais de alguns fragmentos da linguagem natural, ou seja, as sentenças declarativas de uma linguagem natural possuem formas lógicas subjacentes que são indicadas pela linguagem formal. Outros ${ }^{3}$ defendem que sentenças declarativas expressam proposições e as fórmulas das linguagens formais mostram as formas dessas proposições. Nesse sentido, a linguagem lógica apenas explicita a estrutura subjacente à linguagem ordinária. Supõe-se assim que um raciocínio em linguagem natural é válido se as formas que subjazem às sentenças constituem um argumento válido.

Ao nos debruçarmos sobre as nuances que perpassam o estudo do raciocínio, além da possibilidade de falarmos sobre a estrutura lógica subjacente ao mesmo, existem alguns aspectos que precisam ser levados em conta. Intuitivamente somos inclinados a pensar que o raciocínio é um processo interno, ou seja, se passa somente a nível intrapessoal em que um sujeito conscientemente engaja-se a refletir, a inferir e a deliberar. Esse é um aspecto pertinente à atividade de raciocinar, contudo existem outros aspectos que precisam ser considerados. Vejamos, a seguir, alguns desses elementos.

\section{Raciocínio interno e raciocínio externo}

Primeiramente, se levarmos em conta que o raciocínio pode ser classificado como intrapessoal ou interpessoal, podemos designá-lo respectivamente, como interno ou externo. Resumidamente, podemos dizer que o raciocínio pode ser caracterizado como um pensamento responsavelmente conduzido, guiado pela a avaliação das razões que o embasam com o objetivo de encontrar respostas para suas questões a partir das informações iniciais (Richardson, 2014). Porém, de que maneira ocorre esse processo? Aparentemente, ele pode ocorrer em duas esferas distintas, quais sejam: na esfera interna e na esfera externa ao sujeito. O raciocínio interno é do tipo que uma pessoa faz individualmente, isto é, que se refere às deliberações pessoais.

\footnotetext{
${ }^{3}$ Montague (1974), Davidson (1984), Lycan (1984) apud Shapiro (2013). 
Enquanto o raciocínio dito externo é do tipo que normalmente envolve mais pessoas no processo, por exemplo, quando estamos barganhando ou tentando convencer uma pessoa, negociando ou simplesmente justificando alguma coisa para alguém. É importante ressaltar que, mesmo em se tratando de raciocínio externo, existe uma parcela que se processa internamente. Desse modo, há uma mescla entre uma parte do raciocínio que se processa internamente e outra parte do raciocínio que é externalizada ou compartilhada. No exemplo da barganha, existe uma parte que se processa internamente e outra que se processa em contato com o outro na argumentação para se conseguir o que se deseja. Quanto ao raciocínio interno em um processo deliberativo, às vezes ele serve para externalizar nossas dúvidas a outra pessoa e, ao ouvir sua opinião, passamos a perceber a questão de outra maneira, contribuindo, assim, para uma conclusão diferente da que teríamos chegado se não tivéssemos manifestado nossas dúvidas.

Evidentemente, as coisas não são tão simples assim. Diferentemente da assertiva de que o raciocínio correto é o raciocínio lógico, em que aparentemente nosso raciocínio é conduzido por regras de inferência conscientes e bem definidas, muitas vezes raciocinamos, chegamos a conclusões, mas nem sempre temos clareza do processo que seguimos, nem, tampouco, chegamos a conclusões somente através do processo inferencial do raciocínio. Quando o raciocínio é estudado sob o viés da psicologia, há a possibilidade de se pensar que existem aspectos do raciocínio que são inconscientes (Harman, Mason e Sinnot-Armstrong, 2009). Assim, nem sempre é evidente os caminhos que seguimos até chegarmos às nossas conclusões. Como veremos mais adiante, às vezes existe uma parte de nosso raciocínio que não encontra justificativas claras e racionais para as conclusões a que chegamos, isso pode ser um indicativo de que existem outros aspectos que podem compor o nosso raciocínio, além das razões, dentre esses elementos podem estar envolvidos nossas intuições, sentimentos, emoções. Então é possível que em nosso raciocínio exista uma parte conduzida por razões e uma outra orientada por nossas intuições e emoções e, dependendo das conclusões a que chegamos o raciocínio pode ser diferenciado entre teórico ou prático como veremos a seguir.

\section{Raciocínio teórico e raciocínio prático}

O que diferencia o raciocínio entre teórico e prático? O raciocínio teórico pode ser compreendido como uma reflexão direcionada a resolução de questões que a priori não estão diretamente relacionadas a questões práticas. Um exemplo dessas questões é o que concerne a explicações, análises e predições que não visam necessariamente uma conclusão do que se 
fazer, ou de que maneira agir. O raciocínio teórico busca uma compreensão e reflexão sobre o que ocorreu e porque ocorreu ou sobre as possibilidades de que algo ocorra no futuro (Wallace, 2014). Nesse sentido, Harman, Mason, Sinnot-Armstrong (2009) referem-se ao raciocínio teórico como inferencial e que pode, na maioria das vezes, exercer uma influência na mudança de nossas crenças. Geralmente, nesse processo, uma pessoa começa o raciocínio com um conjunto de crenças e após a reflexão novas crenças podem surgir e outras serem abandonadas.

Em contraste, o raciocínio prático é prático na medida em que se apresenta como uma reflexão do que deve ser feito ou do que é o melhor a ser feito. Desse modo, o raciocínio se inicia a partir de uma questão normativa, de um desejo ou também a partir de uma crença e pode ter como resultado a decisão do que fazer. Notemos que enquanto o raciocínio teórico resulta em uma crença, o raciocínio prático pode resultar em intenções de ações ou mesmo na efetivação dessas ações.

Como podemos perceber, quando pensamos na conclusão desses dois tipos de raciocínio, existe um consenso sobre a conclusão do raciocínio teórico, cuja conclusão é uma crença, no entanto, não existe um consenso quanto a conclusão do raciocínio prático. $\mathrm{O}$ resultado do raciocínio prático, de acordo com alguns pode ser uma ação, outros defendem que é uma intenção. Assim, podemos dizer que comumente a racionalidade prática é associada à ação, seja de uma forma direta ou seja de uma forma indireta. Refletir e decidir o que fazer e como fazer é uma questão prática, e portanto, existe uma possibilidade de que o resultado de uma deliberação prática seja uma ação. Vejamos o seguinte exemplo,

Premissa 1: Eu quero passar no exame de português (desejo)

Premissa 2: Se eu estudar bastante então eu passarei no exame de português (crença)

Conclusão: Eu devo estudo bastante (intenção de ação ou a ação de estudar?)

Nesse raciocínio, nós partimos de dois estados mentais o desejo de conseguir algo e a crença do que é necessário para conseguir o que desejamos e chegamos à conclusão do que deve ser feito para que o desejo ou objetivo seja alcançado. Para alguns como Dancy(2004) essa conclusão significa a ação de estudar bastante a fim de alcançar o objeto desejado. Entretanto, percebemos que essa visão não é isenta de problemas, pois a conclusão de que se deve estudar bastante não significa necessariamente a ação de estudar bastante. Vejamos que existe uma diferença entre o conteúdo proposicional da conclusão e o ato de estudar. As ações geralmente requerem muito mais do que apenas um conteúdo proposicional, nesse sentido, elas 
se efetivam de fato na realidade através de algum movimento que se inicia dando início a um processo de transformação, no qual se parte de um estado inicial e através da ação se chega a outro estado final. No entanto, no raciocínio (se usarmos o termo de acordo com a lógica) encontramos relação de consequência lógica entre as proposições, ou seja, entre as premissas e a conclusão. No exemplo acima, antes de efetivar a ação de estudar bastante, houve um componente mental que antecedeu a ação. Esse componente pode ser uma proposição declarativa "eu estudo bastante", pode ser uma proposição normativa "eu devo estudar bastante", mas elas não indicam necessariamente a efetivação da ação de estudar bastante, que inclui a atitude de dedicar várias horas por dia a apreender os conteúdos de português. Percebemos que existe uma diferença entre a conclusão do que se deve fazer e a efetivação dessa conclusão. A conclusão do que fazer configura-se como um conteúdo proposicional e a ação de fazer o que foi determinado pela conclusão configura-se como um movimento o qual tem a capacidade de mudar o estado de coisas inicial.

Assim sendo, para passarmos do conteúdo proposicional de uma conclusão do raciocínio prático para a efetivação dessa conclusão propriamente dita, precisamos de algo mais, ou seja, precisamos de razões ou elementos que nos permitem a efetivar as conclusões a que chegamos nos raciocínios que fazemos.

\section{As razões para as ações}

No domínio mais prático do raciocínio, quando nos engajamos na atividade de deliberação sobre o que fazer, na maioria das vezes decidimos agir de uma maneira em detrimento de outra, e fazemos baseado em determinadas razões, ou seja, existem razões que nos levam a escolher o que escolhemos. Em muitas situações, temos razões que justificam nossas escolhas e nossas ações. Assim, nós nos engajamos em raciocínio prático, pois deliberamos sobre o que fazer e como fazer. Geralmente agimos à luz de razões as quais podem explicar ou mesmo justificar essas ações (Alvarez, 2016) e podem também nos motivar a agir da forma que agimos.

As questões que envolvem razões ou, mais especificamente, as questões que envolvem razões para a ação são objeto de estudo de muitos filósofos que tentam compreender a natureza dessas razões. Para tanto, uma das categorizações que mais comumente encontramos é a distinção da forma como as razões podem apresentar-se em relação as ações. Assim, para Dancy (2000: 2-3 apud ALVAREZ, 2016) dependendo da noção de razão que empregamos ela pode 
ser considerada como uma razão motivadora da ação ou uma razão normativa (que reflete sobre se seria uma boa razão para a ação). Logo, a mesma noção de razão pode ser usada para responder duas perguntas diferentes: uma pergunta concerne ao problema se existe uma boa razão para se efetivar uma determinada ação. Nesse caso, teríamos uma questão normativa. A outra pergunta seria se a razão serve como motivação para a efetivação da ação, caracterizandoa assim, como uma razão motivadora.

Assim, dependendo do foco dados às razões que alguém tem para agir ela se caracteriza como normativa ou motivadora. De uma maneira prática, imaginemos uma pessoa que concluiu que deve se tornar vegana baseada nas seguintes razões: as questões ambientais recorrentes da indústria pecuária, os malefícios da carne à saúde, o maltrato aos animais, etc. ou seja, as boas razões para fazer, uma vez que racionalmente falando, todos as pesquisas revelam a relação existente entre a indústria pecuária e as consequências danosas ao planeta e a saúde. Entretanto, podem existir pessoas que mesmo com base nas razões normativas não conseguem efetivar suas decisões. Quantas pessoas já ouvimos dizer "eu preciso me tornar vegana, porque compreendo os benefícios que isso traria, mas ainda não consigo". A pessoa tem consciência das implicações de seu consumo, ou seja, tem razões normativas para fazê-lo, mas não consegue. Falta-lhe algo que lhe impulsione a efetivar aquilo que se tem razões para fazer, assim sendo, se o foco da sua atenção se volta para a questão de quais razoes realmente são motivações para se tornar vegana, ou seja, o que embasa o seu desejo, a sua determinação de se tornar vegana, as razões se configuram como motivadoras. Assim, "a distinção entre razão normativa e motivadora, por conseguinte, nos capacita a separar a questão de quais razões motivam os agentes a agirem (uma questão psicológica) e a questão se essas são boas razões: razões que favorecem e justificam suas ações.” (ALVAREZ, 2016, p.03).

Até aqui, fizemos considerações sobre o raciocínio compreendido de uma forma geral, equiparado ao raciocínio lógico-inferencial, entretanto, nos interessa analisarmos sobre o raciocínio moral. Por que este se constitui como um tipo específico de raciocínio?

\section{O raciocínio moral}

Antes de tratarmos da natureza desse tipo de raciocínio, pensemos na seguinte situação: no Brasil, comumente vemos crianças pedindo dinheiro nas ruas dizendo que estão com fome. Pode ser o caso que elas realmente utilizem o dinheiro arrecadado para comprar comida, mas pode ser que elas o utilizem para comprar drogas. Há ainda a possibilidade delas estarem sendo 
usadas por adultos - algumas vezes seus próprios pais - que as exploram para angariar dinheiro. Face a uma situação como essa, é certo darmos dinheiro a essas crianças mesmo quando existe a possibilidade de que elas usem esse dinheiro para comprar drogas ou estejam sendo usadas por adultos ou pais desonestos? Algumas pessoas decidem dar o dinheiro e outras decidem não dá-lo e ambas estão embasadas em razões que as levam a agir da forma que agem.

Imaginemos que duas pessoas P1 e P2 estão na rua e são abordados por um menor que pede dinheiro para comer porque está com muita fome. Nesse momento, as duas pessoas sentem-se incomodadas com a situação e têm que decidir o que fazer, seja ajudando, seja recusando-se a fazê-lo. P1 acredita que, na maioria das vezes, as crianças na rua pedem dinheiro para comprar drogas. Então, de acordo com suas crenças, P1 decide não dar dinheiro ao menor, uma vez que ela não está convencida do real motivo para o pedido - se é realmente para o menor alimentar-se.

Ao mesmo tempo, P2 também pensa sobre o que fazer. Na sua cabeça, ela pensava na máxima de que devemos fazer aos outros aquilo que gostaríamos que os outros nos fizessem, que se ela estivesse com fome o que mais desejaria era que alguém lhe desse o que comer, mas, ao mesmo tempo, ela estava consciente de que o pedido do menor poderia ter a intenção de usar o dinheiro para outros fins. Nessa perspectiva, P2 não acha certo lhe dar o dinheiro para que ele não tenha a possibilidade de usá-lo para comprar drogas, mas P2, da mesma forma, não acha certo ignorar a possibilidade de que essa criança esteja realmente com fome. Se ela ignorasse esse suposto fato, ela não conseguiria ficar com a consciência tranquila, sentir-se-ia mal por ter negado ajuda a alguém que estava precisando. Assim, depois de refletir, P2 acredita que deve ajudar a criança, não com o dinheiro porque ela não julga que seja o melhor a ser feito, mas decide pagar uma refeição para a criança. Decidido isso, P2 acompanha a criança até o restaurante mais próximo e lhe compra uma refeição.

Esse exemplo demonstra que duas pessoas em face da mesma situação possuem maneiras diferentes de deliberar. As nossas deliberações morais têm um aspecto subjetivo que concerne à maneira como cada agente interpreta e lida com as situações que exigem uma decisão. De um ponto de vista objetivo, não podemos dizer quem estava certo, se P1 ou P2, pois ambos possuíam razões, crenças e princípios que embasaram suas decisões. Então, pode-se considerar que as nossas decisões morais são de responsabilidade de quem as toma, ou seja, somos responsáveis pelas escolhas que fazemos.

Decidir o que fazer baseado no que julgamos ser certo ou errado, decidir como fazer e avaliar as consequências dos nossos atos são coisas que estão relacionadas e compõem o que 
chamamos de raciocínio moral. Então, como mostramos no início desse trabalho, o raciocínio é comumente assumido como raciocínio lógico ou inferencial, mas será que esses processos são semelhantes ao que ocorre com o raciocínio envolvido nas nossas questões morais? Será que o modelo dedutivo de raciocínio é suficiente para representar o nosso raciocínio sobre o que devemos ou não fazer em todas as situações em que uma deliberação é requerida? Será que o indivíduo passa sempre por um processo argumentativo abstrato antes de tomar uma decisão sobre o que fazer? Ou será que, às vezes, decidimos o que fazer de forma imediata sem que passemos por um processo inferencial? A partir dessas questões podemos pensar que o termo 'raciocínio' utilizado para se referir ao processo interno relacionado a tomadas de decisões e deliberações morais pode não ser utilizado no mesmo sentido que empregado nas teorias formais ${ }^{4}$, visto que essas teorias não são nem descritivas, no sentido de descrever o que e como nós devemos fazer, nem, tampouco, normativas, no sentido de dizer o que nós devemos fazer (Harman, 2011). Ou seja, de acordo com essa visão, existe uma grande diferença entre as teorias formais e as nossas deliberações morais.

De um ponto de vista bastante prático, uma pessoa reflete a partir de crenças, princípios, premissas, que ela considera verdadeiros, mas ela raramente se pergunta sobre o que os torna verdadeiros. Pelo contrário, a pessoa assume a veracidade desses componentes e delibera a partir deles. Então, de que forma esses componentes fazem parte das nossas deliberações? Lembremos que, no exemplo acima, P1 e P2 partiram seus raciocínios de componentes distintos, isto é, de algumas crenças e princípios diferentes, bem como pudemos observar que outros componentes entraram em cena de forma a conduzir os raciocínios que resultaram também em decisões distintas. Assim, existem alguns conteúdos mentais que podem figurar no processo das nossas deliberações morais.

\section{Os conteúdos mentais que podem participar do nosso raciocínio moral.}

Convém novamente indagar: quais os componentes mentais que podem participar das nossas deliberações morais? Existem algumas teorias que tentam explicar o funcionamento do

\footnotetext{
${ }^{4}$ Um exemplo dessas teorias formais é a lógica matemática, mesmo a lógica deôntica, que se apresenta como a lógica do dever não consegue abarcar todas as nuances que perpassam as questões de dever na prática, um desses exemplos é sua impossibilidade de lidar com os conflitos morais. Quando se diz que elas não são descritivas é no sentido de que elas podem formalizar uma proposição que enuncia uma obrigação, mas não descreve como devemos fazer para efetivar essa obrigação. Em suma o que Harman defende é que as teorias formais estão longe de formalizarem todos os aspectos envolvidos nas questões deliberativas, por isso ele critica a vertente puramente racionalista logicista do raciocínio moral.
} 
nosso cérebro ou ainda de que maneira ele processa certas informações e produz os nossos julgamentos e crenças. Com efeito, existem muitos conteúdos representacionais no nosso cérebro, por exemplo, quando pensamos em 'bondade' algumas representações se apresentam à nossa mente. Mesmo não tendo uma definição formal desse conceito, sabemos identificar quando as pessoas agem com bondade. Assim, independentemente de termos um conhecimento e uma definição formais dos conceitos, sabemos que eles são essenciais para qualquer atividade racional, seja no âmbito do raciocínio teórico ou do raciocínio prático. Todavia, sabemos que não são apenas os conceitos os elementos que compõem a nossa atividade deliberativa.

Além dos conceitos, os desejos, as crenças e as nossas emoções são elementos que podem influenciar os nossos raciocínios, sobretudo o nosso raciocínio moral. O nosso desejo de que alguma coisa aconteça de determinada forma, ou de que o mundo seja de determinada maneira, ou de que as pessoas ajam de tal modo tem influência na maneira como deliberamos. Da mesma forma acontece com as nossas crenças, pois aquilo que acreditamos ser bom ou verdadeiro tem papel significativo nas nossas deliberações. Igualmente, as nossas emoções possuem um papel de destaque na maneira como raciocinamos e formamos nossos julgamentos e deliberações. A fim de caracterizar com mais precisão essa influência, comecemos pelos conceitos morais.

\section{Os conceitos morais}

Os conceitos são elementos constitutivos dos nossos pensamentos, de forma que eles são indispensáveis aos processos psicológicos, como a classificação, a inferência, o aprendizado, as deliberações, etc. (Margolis e Laurence, 2011). Os conceitos podem ser pensados como uma representação mental de algo concreto, a exemplo de uma cadeira, ou abstrato, como a ideia de bondade, os quais nos fazem compreender e descrever a realidade. No exemplo do conceito de cadeira, a compreensão que eu tenho do objeto cadeira é diferente da compreensão que eu tenho do objeto mesa. Cadeira é um objeto que possui um assento e normalmente é utilizado para sentar, enquanto que mesa é um objeto que possui uma parte plana que é utilizado para fazer as refeições. Uma vez apreendido determinado conceito, ele pode ser aplicado a coisas da mesma categoria, independentemente do fato de que cada objeto pode, dentro do mesmo conceito, apresentar outras peculiaridades. Os conceitos morais, por outro lado, são entidades abstratas que, diferentemente de uma cadeira, não podemos capturar através da percepção. Não vemos o bem ou o mal da mesma forma que vemos uma mesa ou uma 
cadeira, mas existe em cada um de nós a ideia do bem e a ideia do mal, e é por isso que, em geral, sabemos o que é certo e o que é errado. Todavia, a questão acerca de como aprendemos o que é certo e o que é errado, não obstante sua relevância, não será por nós investigada aqui.

$\mathrm{Na}$ filosofia, o debate sobre os conceitos em geral parece interminável, revelando uma riqueza de perspectivas que envolvem a ontologia dos conceitos, sua natureza, as visões empiristas e nativistas dos conceitos, a relação entre os conceitos e a linguagem natural, entre outros aspectos (Margolis e Laurence, 2011). Assim, assumiremos os conceitos como elementos constitutivos dos nossos pensamentos e indispensáveis aos nossos processos de raciocínio moral. Desse modo, partimos do pressuposto de que não é possível deliberarmos sobre alguma coisa se não temos a noção sobre o que estamos deliberando. Não podemos escolher ou avaliar o que é certo ou errado se não tivermos o conhecimento, ou uma noção do que é certo e do que é errado.

Se levarmos em consideração a situação política brasileira e pedirmos a alguém que manifeste sua opinião sobre o que ela pensa dos nossos representantes políticos, é possível que essa pessoa afirme que "muitos dos nossos políticos são ladrões" e para que ela emita essa avaliação, a mesma deveria estar ciente dos acontecimentos e do que significa cada termo que ela usou na sua avaliação. Para essa pessoa emitir esse julgamento, ela utilizou-se de alguns conceitos que a permitiram elaborar sua opinião. O processo de raciocínio poderia ter ocorrido da seguinte forma:

Fato 1: muitos políticos foram acusados de apropriarem-se do dinheiro público.

Fato 2: existem provas que comprovam a apropriação do dinheiro público por parte dos políticos.

Crença: se alguém apropria-se de algo que não lhe pertence, então esse alguém é ladrão.

Logo, muitos dos políticos são ladrões.

Para fazer esse encadeamento de palavras que expressam um sentido, a pessoa utilizase de vários conceitos que supostamente ela compreende. E se, com os elementos do raciocínio acima, em vez dessa pessoa concluir que "muitos dos nossos políticos são ladrões" ela concluísse que "eu gosto de sorvete", essa conclusão seria coerente com os elementos que faziam parte do seu raciocínio? É notório que a resposta é "não". Então, a clareza, a compreensão dos conceitos e palavras que fazem parte do nosso raciocínio são indispensáveis 
para que esse ato de pensar e avaliar ocorra de uma forma coerente. Assim, podemos dizer que os conceitos morais são indispensáveis para nossa atividade de raciocinar moralmente, no entanto eles não são os únicos elementos que fazem parte das nossas deliberações. Como vimos, muitas vezes o nosso raciocínio começa a partir de um desejo.

\section{Os desejos}

Desejar é um estado mental particular e familiar a qualquer pessoa que já sentiu o desejo de, por exemplo, comer alguma coisa específica, possuir algo ou obter conhecimento. Assim, usamos a palavra desejo relacionada a diferentes situações. Mas, será que o desejo de comer alguma coisa equivale ao mesmo estado mental de alguém que deseja obter conhecimento? $\mathrm{O}$ que coloca todas essas necessidades dentro da categoria desejo? Ou seja, o que caracteriza esse estado mental que chamamos de desejo? Todos esses estados mentais denominados desejos são idênticos no que concerne a serem estados mentais de 'pró-atitude' (Schroeder, 2015), isto é, uma atitude mental favorável direcionada a ação para se obter o que é desejado. Assim, "Desejar é um estado mental que é comumente associado com diferentes efeitos: uma pessoa com um desejo tem uma tendência a agir de uma certa maneira, a sentir de uma certa maneira e a pensar de certa maneira" (SCHROEDER, 2015, p. 01). A pessoa que deseja tem a tendência a agir de forma a realizar esse desejo. Dessa forma, ela pode experimentar diferentes sentimentos em relação a seu desejo, sentir a ansiedade de que seu desejo seja realizado e, se não for possível realizá-lo de imediato, o desejo ocupa os pensamentos da pessoa atraindo o foco para o que ainda não foi realizado.

Atualmente, ainda existem muitas controvérsias quanto à origem dos desejos. Para alguns autores, como é o caso de Pollock (2006), existe apenas um desejo intrínseco e inato que é o desejo do prazer. Outros defendem que nós temos muitos desejos intrínsecos de diferentes tipos, como o desejo do bem dos que amamos, o desejo de felicidade direcionado a outras pessoas, o desejo que nosso time seja campeão, etc.. No entanto, nessa variedade de desejos existem alguns que são inatos como o desejo por prazer, o de comer e beber, o de carinho, entre outros. Porém, muitos dos nossos desejos intrínsecos não são inatos, como, por exemplo, o desejo de que o nosso candidato a prefeito seja eleito. Certamente esse tipo de desejo não faz parte da estrutura inata da nossa mente (Schroeder, 2015).

Os nossos desejos são estados mentais facilmente identificáveis, porém o mais difícil é compreendê-los. Ora, sabemos que sentimos nossos desejos e que, na maioria das vezes, 
queremos realizá-los e, para tanto, agimos. Nesse sentido, a natureza dos desejos apresenta vários aspectos e que servem de base para várias teorias do desejo. Existem teorias que tratam apenas de um aspecto relacionado ao desejo, como, por exemplo, a teoria do desejo baseada na ação. De uma maneira bem resumida, podemos dizer que essa teoria se assenta sobre o pressuposto de que a disposição para agir é a característica mais essencial dos nossos desejos. Ou seja, para uma pessoa desejar $p$ significa que essa pessoa está disposta a praticar qualquer ação que seja necessária para se alcançar $p$ (Schroeder, 2015). Com efeito, concordamos que uma das nuances que compõem os nossos desejos seja a nossa disposição para realizá-los, todavia nem sempre possuímos a disposição para realizar os nossos desejos, uma vez que é possível que desejemos coisas impossíveis. Nada me impede de desejar ser imortal, ou desejar ser a presidenta da república, ou quem sabe, possuir um avião. Todos esses desejos são plausíveis de fazerem parte do conjunto de desejos de qualquer pessoa, mas não significa que eles são realizáveis. Por mais que eu me empenhe em fazer qualquer coisa para ser imortal esse desejo jamais será realizado na perspectiva corpórea. Desta feita, desejar $p$, contrariamente à teoria supra mencionada, não significa necessariamente que a pessoa esteja disposta a fazer qualquer coisa que seja necessária para alcançar $p$. Além dessa teoria embasada na ação, sabemos que existem outros aspectos que estão relacionados aos desejos, os quais não nos interessa tratarmos aqui.

Para nós um ponto fundamental é a questão de que maneira os desejos atuam na constituição das nossas deliberações. A despeito das classificações de desejos encontrados na literatura $^{5}$, Arpaly e Schroeder (2014) tratam dos desejos intrínsecos, pois estes são considerados os desejos relacionados à moralidade. Ter os desejos certos, ou seja, ter desejos intrínsecos pelo que é certo ou pelo que é bom é o que nos possibilita agir por razões morais, agir de maneira louvável e ser virtuoso. Para eles, ter esses desejos é o que caracteriza a boa vontade $^{6}$. Assim, ter a boa vontade (o desejo de fazer o bem e fazer o certo), ou seja, ter a capacidade de agir pelas boas razões, de uma maneira laudável e virtuosa, é simplesmente uma

\footnotetext{
${ }^{5}$ De uma forma bastante simplificada, os desejos são divididos em intrínsecos, instrumentais e realizadores. O que é intrinsecamente desejado, o que é desejado pelo seu próprio bem, o que é desejado como um meio para a realização do que é intrinsecamente desejado, ou seja, como um instrumento para o fim do desejo intrínseco. E, por último, os desejos realizadores que são os desejos relacionados a realizações dos fins que são intrinsecamente desejados.

${ }^{6} \mathrm{O}$ conceito de boa vontade utilizado por Arpaly e Schroeder (2014) está intimamente relacionado ao desejo intrínseco de se fazer a coisa certa, ou fazer o que é bom de acordo com as razões certas. Percebemos que esse conceito se diferencia do conceito Kantiano de boa vontade, que muito simplificadamente podemos dizer que se trata daquela vontade que leva o agente a agir por dever.
} 
questão de desejar as coisas certas. Uma vez que tratamos dos desejos, precisamos também investigar as crenças que lhe são associadas.

\section{As crenças}

Outro componente que consideramos fundamental nas nossas deliberações morais é aquele que designamos de crenças. De uma maneira bem simplificada e de acordo com uma definição bastante utilizada entre os filósofos analíticos sobre o que é uma crença, assumiremos a definição de que uma crença é uma atitude positiva em relação a uma proposição ou estado de coisas. Crer em P é admitir P como verdadeiro (Chignell, 2016). Assim, inspirados no problema da indução reapresentado por Hume, podemos dizer que crer que o sol nascerá amanhã é ter como verdadeiro que o sol nascerá amanhã. Temos evidências, por meio da observação ou experiência, de que o sol tem nascido todos os dias até hoje, então acreditamos que o sol também nascerá amanhã. Realmente não parece fazer nenhum sentido acreditarmos em algo que admitimos ser falso. Com efeito, há um aspecto relacionado às nossas crenças que é digno de nota, qual seja: cada crença que nós temos, da mais simples a mais complexa, vai além das nossas experiências quando vistas como um guia para nossas ações (Clifford (1876) apud Chignell, 2016). Por exemplo, pensemos acerca de como decidimos ou não de fazer um seguro para nosso carro. Pode ser o caso de que, até hoje, não houve nenhuma situação em que se precisou usar um seguro desse tipo, mas dada as evidências do que acontece com outras pessoas, acreditamos que existe a possibilidade de que alguma coisa aconteça com nosso carro e, por isso, mesmo sem ter a experiência de algo que aconteceu, somos levados a crer que pode acontecer algo e que, por isso, precisamos do referido seguro. A decisão de contratar um seguro, nesse caso, não é baseada em alguma experiência pessoal vivida, mas na crença de que existe a possibilidade de algum acidente ou dano vir a acontecer.

Muitas vezes nossas crenças são guias para nossas ações. Comumente, um agente moral possui um conjunto de crenças que faz parte de suas deliberações. Tomemos como exemplo uma pessoa que é testemunha de Jeová, uma das crenças que essa pessoa possui, baseada na Bíblia, é que é errado fazer transfusão de sangue e essa crença é justificada pela seguinte passagem: "Abstenham-se do sangue." (Atos, 15:20). Ademais, no site das Testemunhas de Jeová7 encontramos a seguinte explicação sobre esse versículo: "Deus deu aos cristãos a mesma

\footnotetext{
${ }^{7}$ https://www.jw.org/pt/ensinos-biblicos/perguntas/biblia-transfusoes-de-sangue/ 
proibição que deu a Noé. A História mostra que os primeiros cristãos não consumiam sangue, nem mesmo para fins medicinais." De acordo com essa crença, se realmente a pessoa acredita nessa passagem, dificilmente ela decidiria por fazer uma transfusão de sangue. Por isso, temos indícios muito fortes de que as nossas crenças exercem uma influência considerável nas nossas deliberações morais. Mas, será que são realmente as crenças que determinam tal deliberação? Os seguidores de tal religião deixam de receber transfusão pela convicção ou fé religiosa ou por ter medo de transgredir uma lei divina, de pecar, de sofrer alguma censura ou punição? Enfim, precisamos também avaliar o peso das emoções na constituição das nossas decisões e ações morais.

\section{As emoções}

As emoções ou, de uma maneira mais geral, as paixões sempre assumiram um status antagônico e menos privilegiado em relação à razão. Não sabemos se isso se deveu à dificuldade em se estudar e compreender as emoções, mas o fato é que, por séculos, elas foram negligenciadas pela maior parte dos filósofos. O culto à razão reduziu às emoções a um papel secundário e sua função sempre foi vista como algo nefasto, pernicioso. Elas revelavam o aspecto mais bestial do ser humano, por isso não eram dignas de estudo, compreensão e admiração, mas de negação e marginalização. Depois de séculos do desenvolvimento do pensamento ocidental, ainda ouvimos frases do tipo "fulana é tão emocional", como se isso fosse a evidência de algum defeito ou deficiência de caráter. Será realmente que ser emocional ou sentir emoções e paixões são aspectos negativos da nossa condição humana? Porém, alguns filósofos "nadaram contra a correnteza" tradicional e ousaram se debruçar sobre esse aspecto primordial da natureza humana.

Um desses filósofos foi David Hume que é considerado o "filósofo das paixões". Ele se deteve com muito afinco no estudo da natureza humana e causou uma reviravolta no pensamento ocidental. Em um meio em que a razão possuía a supremacia, um status irrevogável que atribuía ao homem uma superioridade, Hume abalou essa tendência ao defender que a razão não participa diretamente das ações humanas,

Uma vez que a moral influencia as ações e emoções, segue-se que esta não pode derivar da razão, pois a razão por si, como já provamos, nunca pode exercer tal influência. A moral excita paixões e produz ou impede ações. A razão por si é totalmente impotente neste aspecto. Logo, as regras da moral não são conclusões da nossa razão (HUME, 2001, p. 572). 
Como já indicamos, o raciocínio correto era tido como o raciocínio lógico, no entanto, para Hume, as paixões, e não a razão, são a causa da moralidade. “A moral não pode resultar de inferências e conclusões do entendimento, pois este não possui qualquer influência sobre os afetos nem, tampouco, se mostra capaz de motivar as ações dos indivíduos" (PEQUENO, 2012, p.90). O entendimento seria responsável pelos juízos de verdade e falsidade, porém incapaz de suscitar desejo ou aversão. Por outro lado, a abordagem racionalista expressa que:

o conhecimento moral e os julgamentos morais são atingidos através do processo de raciocínio e reflexão (Kohlberg, 1969; Piaget, 1932/1965; Turiel, 1983). As emoções morais como simpatia podem às vezes ser insumos para o processo de raciocínio, mas as emoções morais não são as causas diretas dos julgamentos morais. (HAIDT 2000, p.02)

Contra essa abordagem, Haidt (2000) apresenta o seguinte exemplo: Julie e Mark são irmãos que estão viajando juntos de férias na França. Eles decidem que pode ser divertido fazerem amor. No mínimo isso pode ser uma experiência nova para os dois. Julie já estava tomando anticoncepcional e Mark usaria um preservativo para que não houvesse nenhum risco de gravidez. Os dois gostaram de fazer amor e resolveram fazer novamente, mas decidiram que manteriam isso em segredo. Perguntando sobre o que as pessoas achavam dessa situação, isto é, se elas achavam que estaria tudo bem para os irmãos fazerem amor, as pessoas disseram que era errado e começaram a apresentar razões que demonstravam o erro.

Elas falaram sobre a possibilidade de Julie engravidar, mesmo sabendo que os dois estavam usando contraceptivos; elas argumentaram que os dois poderiam se ferir emocionalmente (mesmo estando claro que foi consensual e que ambos estavam preparados para isso); alguns disseram que "eu não sei, eu não consigo explicar, mas eu sei que é errado" talvez esse "saber" que é errado esteja embasado em uma aversão à ideia de dois irmãos fazerem amor. Como podemos saber que algo é errado sem sabermos realmente por que é errado? Então, podemos pensar na possibilidade de que muitas vezes não se trata realmente de saber que algo é certo ou errado, mas de sentir que algo é certo ou errado. Nesse sentido,

a percepção que temos das ações morais, sejam as nossas ou de outrem, decorre do nosso sentimento de aprovação ou reprovação. E, como a razão não participa da apreciação propriamente dita do bem e do mal, segue-se que nós os aprovamos imediatamente (ou seja, sem mediação racional). Este sentimento moral que nasce em nós decorre de uma impressão original própria à natureza humana: a possibilidade de sentir prazer ou dor. São tais sensações que nos permitem diferenciar o bem do mal guiando-nos para aquilo que 
suscita o prazer e desviando-nos daquilo que gera a dor. (PEQUENO, 2012, p. 99)

Acreditamos na hipótese de que as emoções têm um papel fundamental nas nossas deliberações morais, que existe uma ligação entre as nossas emoções e nossos julgamentos morais e que são elas que nos guiam a fazer o bem, a escolher o que é certo. Existem evidências muito fortes que embasam a teoria de que as emoções são necessárias para o desenvolvimento moral dos indivíduos. Ademais, se as nossas escolhas morais fossem feitas apenas embasadas em processos envolvendo a capacidade racional, pessoas com deficiências emocionais, como os psicopatas, por exemplo, não seriam criminosos. De acordo com Prinz (2004), os psicopatas apresentam deficiência de emoções negativas, como medo e tristeza, e raramente experimentam essas emoções, e quando isso acontece é de forma menos intensa do que as pessoas em condições emocionais normais. Diferentemente das outras pessoas, os psicopatas não mostram qualquer perturbação com fotografias ou casos que nos causam aflição. São incapazes de sentir qualquer emoção negativa básica.

\section{Os princípios morais}

"Faça aos outros o que você gostaria que eles fizessem a você". Essa famosa regra de ouro é muitas vezes evocada quando pensamos como devemos agir em relação aos outros. Assim, por exemplo, quando pensamos em mentir para alguém, somos capazes de pensar em como nos sentimos nas situações em que alguém mentiu para nós. Nela parecem estar contidos todos os princípios que podem reger as nossas ações morais. Trata-se também de um princípio básico para uma boa conduta moral que recorre a nossas emoções, nossa sensibilidade e nossa capacidade de nos colocarmos no lugar dos outros. Existe, com efeito, uma gama imensa de enunciados que são tomados como princípios morais do tipo: "não matarás", "não roubarás", “cumpra suas promessas", “aja de forma a sempre promover o bem”, só para citar alguns. Aparentemente não poderíamos pensar em questões morais sem recorrermos aos princípios morais como guias que nos ajudam a fazer as nossas escolhas normativas. Todavia, apesar de parecer algo inconcebível pensar em uma moralidade em que os princípios morais não sejam fundamentais, existem questões que suscitam a discussão sobre a real necessidade dos princípios para as nossas deliberações.

Para entendermos o papel que os princípios morais podem ter em nossas deliberações, 
precisamos antes compreender o que são os referidos princípios. Existem duas maneiras de se compreender o que são os princípios morais: há uma concepção absolutista ou generalista e uma outra designada de contributiva. A concepção absolutista, "leva um princípio moral a ser uma reivindicação universal de forma que todas as ações de um certo tipo são universalmente certas ou erradas" (VÄYRYNEN, 2016, p. 04) ${ }^{8}$. Um princípio absoluto é aquele que é o caso em qualquer circunstância. Por exemplo, mentir é all things considered ${ }^{9}$ errado. Deste modo, não importa a situação: mentir será sempre errado!

Por outro lado, existe outra concepção de princípio moral dito contributivo (Väyrynen, 2016). Um princípio contributivo é aquele que contribui ou favorece que o sujeito faça ou não algo. Por exemplo, mentir é pro tanto ${ }^{10}$ errado. Normalmente, mentir é errado, mas podem existir circunstâncias em que mentir não é errado, ou seja, circunstâncias em que o princípio de não mentir pode ser derrogado por outro princípio de maior relevância. Por exemplo, mentir não seria errado em uma situação em que alguém precisasse mentir para não morrer, em circunstâncias normais o ato de mentir seria julgado como algo errado. Percebemos que essa perspectiva contributiva permite que mais de um princípio entre em jogo nas nossas decisões, uma vez que eles são parciais, pois cada um concerne a um determinado aspecto da situação. $\mathrm{E}$ a questão se a ação é certa ou errada vai depender do equilíbrio entre o certo e o errado presentes em tal ação.

Qual seria então o papel dos princípios nas nossas decisões morais? Uma possibilidade muito forte é a de que os princípios podem funcionar como guias para as nossas ações quando nos encontramos em face da necessidade de julgar o que é certo ou errado, ou ainda o que devemos ou não fazer. Naturalmente, temos uma inclinação a pensar que, ao agirmos guiados pelos princípios, temos a garantia de estarmos agindo corretamente, mas nem todos compartilham dessa visão. Contrário a essa visão encontramos o particularismo moral. Esse quando apresentado em sua forma mais forte consiste na defesa de que não existem princípios morais defensáveis e que o raciocínio moral não consiste em aplicar os princípios morais em

\footnotetext{
${ }^{8}$ Versão online preprint de um artigo cuja versão final será publicado em The Oxford Handbook of Reasons and Normativity, ed. Daniel Star. Disponível em: http://www.personal.leeds.ac.uk/ phlpv/papers/RMP.pdf. Acesso em: 08 mai. 2017.

${ }^{9}$ Essa expressão pode ser traduzida como “considerando-se todas as coisas". Assim, dizer que algo é errado all things considered significa dizer que em qualquer situação em que esse algo se apresente sempre será o caso dele ser errado.

${ }^{10}$ A expressão pro tanto é utilizada para designar um caráter parcial ou que pode favorecer algo sem, no entanto, ser determinante. Por exemplo, eu adoro bolo de chocolate, mas eu preciso cuidar da minha saúde por causa de uma labirintite, então eu evito comer bolo de chocolate. Assim, podemos dizer que o fato de eu adorar bolo de chocolate é uma razão pro tanto (que favorece) que eu coma bolo de chocolate, mas o fato de que eu preciso cuidar da minha saúde é uma razão determinante (all things considered) para não comer bolo de chocolate.
} 
casos particulares, bem como a pessoa moralmente perfeita não é aquela concebida como uma pessoa de princípios. Mesmo que existam princípios morais, a racionalidade do pensamento moral e os julgamentos morais não dependem de uma disposição adequada desses princípios, de forma que um agente moral precisa mais do que a compreensão da gama de princípios e da habilidade em aplicá-los. Os princípios morais são, na melhor das hipóteses, o suporte ao qual uma pessoa moralmente sensível não recorreria, pois é possível que o uso de tal recurso induzisse tal pessoa ao erro moral (Dancy, 2013). Essa é uma perspectiva bastante interessante, visto que, na prática e dependendo da situação, alguns princípios entram em conflito, e quando isso ocorre o que resolve a situação são outros componentes, como os sentimentos das pessoas e não necessariamente a aplicação de um princípio.

Por outro lado, o generalismo moral defende que existem princípios morais gerais (pode parecer redundante falar em "princípios gerais", uma vez que o conceito de princípio engloba a noção de universalidade ou generalidade). Esses princípios podem ser absolutos, como já vimos, ou contributivos, porém, segundo essa perspectiva generalista, os princípios contributivos devem ser refinados de forma a não permitir exceções. Contrariamente ao particularismo, para os generalistas os princípios morais podem e devem ser usados como guias do raciocínio moral e uma pessoa de princípios é uma pessoa virtuosa.

Se assumirmos uma posição generalista, diremos que os princípios morais são indispensáveis para as nossas deliberações. Nessa perspectiva, qual conceito de moral poderia ser instituído? Se os princípios são vistos em uma perspectiva absolutista, então teríamos que o nosso raciocínio moral seria guiado por princípios morais absolutos. $\mathrm{O}$ que isso implicaria em termos práticos? Por exemplo, supondo que uma pessoa precise com urgência de um medicamento para salvar a vida de seu filho, essa pessoa pede ajuda ao dono da farmácia, pede ajuda às pessoas na rua, mas não consegue nada. Então, por alguns instantes, o dono da farmácia ocupa-se de outras coisas e sai do lugar onde estão os remédios. Nesse momento, a pessoa tem acesso ao remédio, de forma que pode roubá-lo sem que o dono perceba. Ele é uma pessoa honesta, nunca roubou nada antes, entretanto naquela circunstância conseguir esse remédio seria uma questão de vida ou morte. Rapidamente, ele pensa e decide roubar o remédio para salvar a vida do seu filho. A questão é: essa pessoa agiu errado?

Segundo a visão absolutista de princípio, qualquer que fosse a situação, o princípio de "não roubar" deveria ser sempre o guia da ação correta, como diz Kant. Por isso, o fato de salvar a vida do filho não justificaria o roubo do remédio, pois a ação de roubar é all things considered errada, ou seja, roubar é errado independentemente das circunstâncias, mesmo que fosse para 
salvar uma vida. Nessa concepção, seria impossível haver conflito entre princípios. No entanto, em termos práticos, é comum encontrarmos conflitos entre alguns princípios, de modo que há a necessidade de o agente moral apelar a outros meios para solucionar seus conflitos. No caso citado acima, o conflito consistia entre o princípio de "não roubar" e o princípio de "salvar uma vida". Obviamente, nesse caso, o agente atribuiu maior relevância ao princípio de salvar a vida de seu filho.

Diante dos casos práticos ocorridos em nossas vidas, temos inclinação a assumir os princípios contributivos, pois nem sempre é o caso de guiar nossas ações por um princípio sem levar em conta as circunstâncias do momento. Os princípios morais podem ajudar a guiar nossas deliberações até certo ponto, mas outros elementos também colaboram nesse processo de raciocínio para decidir o que devemos fazer quando as nossas ações morais são requeridas.

$\mathrm{Na}$ visão particularista mais radical, encontramos a afirmação de que os princípios morais não são necessários para deliberarmos. Nesse sentido, podemos considerar que uma pessoa evita ser guiada por princípios e ainda assim é capaz de agir racionalmente e por razões consistentes (RIDGE e MCKEEVER, 2016). Nesse sentido, o poder de discernir do agente consciente é fundamental para sua deliberação. Convém refletir sobre o que se deve ou não fazer, não mais baseado em um guia ou numa lista do que é certo ou errado, mas fazermos nossas considerações com base em outros elementos. Assim, por um lado, o pai que decidiu roubar um remédio para salvar a vida de seu filho poderia saber que era errado roubar e que seu gesto poderia implicar em prisão. Mas, por outro, ele possuía uma razão muito mais forte, segundo a qual valia a pena correr o risco de ser preso por fazer algo que é considerado errado. Nesse sentido, ele possuía razões suficientes - a vida do seu filho, o amor que sentia por ele para roubar o medicamento. Sobre os contornos e alcance do raciocínio moral e suas conclusões, temos outros exemplos a destacar.

\section{O raciocínio moral e suas conclusões}

Analisemos a seguinte situação. Joana deseja faltar ao trabalho na sexta e no sábado porque quer viajar com o namorado no final de semana, mas, apesar de querer se ausentar, ela não deseja que essas faltas sejam descontadas de seu salário. Então, ela decide falar com sua amiga Luiza, que é médica, e pedir-lhe um atestado que possa justificar tal ausência. Joana explica a situação a Luiza e lhe garante que ninguém saberá que ela faltou ao trabalho porque foi viajar, que ninguém nunca saberá que ela não estava realmente doente. Luiza ouve a 
explicação de Joana e pensa no que fazer, uma vez que gostaria muito de ajudar sua amiga. Com base nisso, ela reflete utilizando as seguintes proposições:

(P1) Joana é uma amiga muito querida e eu desejo ajudá-la. (Desejo de ajudar a amiga)

(P2) Eu acredito na verdade e não desejo mentir sem que seja em uma necessidade extrema. (Desejo de agir corretamente)

(P3) Dar um atestado assegurando que ela está doente consiste em mentir (conceituação da ação)

(P4) Mentir é errado a menos que seja em situações extremas. (Crença)

(P5) Viajar com o namorado não é uma situação de extrema necessidade. (Julgamento sobre a ação)

(P6) Eu me sinto mal por não poder ajudar a minha amiga, mas também me sinto mal com a ideia de dar um atestado falso. (Conflito entre o desejo de ajudar a amiga e o desejo de agir corretamente na profissão).

(P7) dizer um "não" a Joana seria menos danoso, uma vez que são amigas e Joana a entenderia, do que emitir um atestado falso. Ademais, se, de repente, acontecesse alguma coisa (se alguém do trabalho encontrasse a Joana na viagem, por exemplo), as pessoas saberiam que Joana não estaria doente e que o atestado era falso. (Ponderação das possíveis consequências)

(P7) Eu não devo fornecer o atestado a Joana. (Conclusão)

Como podemos perceber, vários elementos passam pela cabeça de Luiza e ela está enredada em dois desejos conflitantes. Ademais, por causa da relação de amizade, ela sente o desejo de poder ajudar Joana, mas existe em sua conduta moral o desejo de ser sempre veraz. Aqui entram em cena outros elementos, como a crença de que a mentira só é aceitável em situações de extrema necessidade. Portanto, ela julga que a situação de Joana viajar com o namorado não é uma situação de extrema necessidade para justificar uma mentira. Como conclusão desse raciocínio, Luiza chega à decisão de que não deve fornecer o falso atestado a Joana. Nosso interesse aqui consiste em analisar o processo que conduz à conclusão do raciocínio moral. Nesse caso particular, Joana chegou à conclusão do que deveria fazer (negar o atestado a Joana). Com efeito, a conclusão de um raciocínio moral é geralmente relacionada ao que devemos ou não moralmente fazer. 
Na seção sobre o raciocínio prático, vimos que existem no mínimo duas possibilidades em relação à conclusão do raciocínio prático. Ora, assumimos o raciocínio moral como um tipo de raciocínio prático e, nessa perspectiva, como poderíamos entender as proposições que denotam a conclusão do processo deliberativo? A frase "Eu não devo dar o atestado a Joana" significa a intenção ou a ação de não dar o atestado a Joana? Significa uma crença normativa de que não ela deve dar o atestado ou significa o julgamento moral de que é errado dar o atestado a Joana?

Concordamos que a deliberação moral está diretamente relacionada à ação, haja vista que deliberamos sobre o que devemos fazer. Porém, conforme já mencionamos, existe uma diferença crucial entre deliberar o que fazer e a ação concretizada. $\mathrm{O}$ fato de concluirmos sobre o que devemos fazer não garante que o faremos, mesmo que exista um caráter obrigatório determinado pelo nosso senso do dever. Ademais, o que leva um agente moral a agir de acordo com sua deliberação? Seria o senso de obrigação? Uma questão metaética importante sobre o raciocínio prático diz respeito ao que chamamos de operadores deônticos (obrigação, permissão, proibição) e de que maneira esses conceitos são determinantes em nossas ações. $\mathrm{O}$ fato de o indivíduo estar diante de um dever ou obrigação significa necessariamente que ele pode e vai efetivar a ação prescrita?

Existe um princípio deôntico, largamente aceito, também conhecido como o princípio kantiano ${ }^{11}$, que diz que "dever implica poder". Assim, teoricamente, podemos até cogitar essa relação de implicação, no entanto quando passamos ao nível prático da vida nem sempre o dever implica poder. É certo que, às vezes, concluímos que devemos fazer uma coisa, mas não podemos fazer o que deliberamos por inúmeras razões. Nesse sentido, podemos pensar na possibilidade de que, em muitas situações, podemos decidir agir em concordância com o que deliberamos e podemos agir imediatamente após deliberar ou podemos levar mais tempo entre a deliberação e a ação propriamente dita. Podemos, por exemplo, deliberar hoje que devemos

11 O princípio deôntico "dever implica poder" (ought implies can) estabelece o link entre obrigação e possibilidades, apesar de ser associado com Kant, essa associação é questionada (Feis, 2012). Existem diversas interpretações que lhe concernem, mas a principal tem como base a expressão latina ad impossibilia nemo tenetur que significa que ninguém é obrigado a fazer o impossível, ou seja, podemos descartar uma obrigação quando não temos a possibilidade de efetivá-la. Entretanto, outros interpretam dizendo que o fato de se ter o relevante "pode" (can), não existe a possibilidade de não se fazer o que se tem obrigação de fazer. Apesar de ser um princípio largamente aceito, é também fonte de muitas discussões, a título de esclarecimento, como essa terminologia "princípio kantiano" é utilizada na literatura de dilemas morais, a utilizaremos aqui nesse trabalho para designarmos o princípio deôntico "dever implica poder" de forma que não adentraremos na discussão sobre sua relação com os preceitos kantianos. Para aprofundamento nesse tópico ver: STERN, R., Does 'ought' imply 'can'? And did Kant think it does? _Utilitas_ 16 (1):42-61. (2004). 
pagar um imposto e ter que esperar receber o pagamento do salário para efetivar a ação de pagar.

Nesse sentido, temos dificuldades em admitir que o resultado do raciocínio moral seja uma ação. Entretanto, quando pensamos na possibilidade de que o seu resultado seja uma intenção, isso nos parece bastante plausível. Temos a intenção de agir conforme deliberamos e, para passar da intenção ao gesto, precisamos estar motivados a agir. O que motivaria, então, alguém a agir de acordo com a sua deliberação? Existem algumas possibilidades de respostas. Assim, uma vez que alguém julga o que seria melhor ou o que deveria fazer, essa pessoa seria naturalmente motivada a agir de acordo com seu juízo, isto é, “quando uma pessoa P julga que seria moralmente certo fazer $\varphi$, ela está ordinariamente motivada a $\varphi$; poderia $\mathrm{P}$ depois se convencer que poderia ser errado fazer $\varphi$ e certo fazer $\psi$, ela ordinariamente cessaria de estar motivada a fazer $\varphi$ e ficaria motivada a fazer $\psi$ " (Rosati, 2016). Por outro lado, para Hume, apenas a crença decorrente do julgamento sobre o que deve ser feito é insuficiente para motivar uma pessoa a agir. Nessa mesma linha, os externalistas defendem que alguns estados conativos devem entrar em cena atuando no movimento entre o julgar o que fazer e a ação. No entanto, também existem agentes que, mesmo sabendo o que é melhor a ser feito, não se sentem motivados a fazê-lo (Rosati, 2016). Concordamos que alguns estados conativos, como é o caso dos desejos, podem exercer uma força motivadora, mas também consideramos a hipótese de que as emoções exercem um papel de grande relevância entre a intenção de agir e a ação executada, ou entre a crença normativa acerca do que se deve fazer e a efetivação dessa crença através da ação.

Quando, através do nosso raciocínio moral, chegamos à conclusão do que devemos fazer, essa conclusão também pode ser pensada como uma crença normativa, ou seja, a crença do que deve ser feito. Porém, qual seria a diferença entre a crença normativa e a intenção de efetivar essa crença? Apesar de serem coisas distintas, existe uma correlação entre elas. Quando concluímos o que deve ser feito, acreditamos que é o que devemos fazer levando-se em consideração todas as informações da situação, nossos valores morais, etc., e assim julgamos que é o melhor a ser feito. Baseado nessa crença, temos a intenção de agir de acordo com o que deliberamos. Assim, podemos dizer que, em geral, a crença normativa e a intenção de agir são componentes que antecedem a ação.

Voltando ao exemplo do raciocínio desenvolvido por Luiza, ao deliberar que "não deveria dar o atestado a Joana", ela primeiramente acreditava que estava fazendo a coisa certa de acordo com suas razões, crenças e princípios. Em seguida, uma vez que ela acredita ter feito 
a escolha certa, ela é inclinada a agir de acordo com essa escolha, ou seja, ela tem a intenção de agir de acordo com seu julgamento. Mas, suponha que Joana também faz um raciocínio e conclui que apresentar um atestado falso no trabalho é errado. O problema é que ela não se importa com isso. Desse modo, ela tem a crença de que sua ação será errada, mas ela não tem intenção de evitá-la, o que evidencia a diferença entre a crença moral e a intenção de agir. Como falamos antes, existe uma distância entre crer o que se deve fazer, ter a intenção de fazer e realmente fazer. Por isso, somos levados a pensar na seguinte hipótese: a conclusão do raciocínio moral é uma crença normativa, seguida de uma intenção e ambas, dependendo da motivação, tem como consequência a ação.

\section{Considerações finais}

Como vimos, o raciocínio em geral é equiparado ao raciocínio lógico dedutivo e pode ser classificado como teórico ou prático, consciente ou inconsciente, externo ou interno. $\mathrm{O}$ raciocínio moral, por sua vez é categorizado como um tipo de raciocínio prático direcionado à deliberação do que se deve fazer, nesse sentido, vários elementos como os conceitos morais, os desejos, as crenças, as emoções e os princípios morais podem participar desse processo deliberativo bem como da ação decorrente da deliberação.

\section{Referências}

ALVAREZ, M., Reasons for Action: Justification, Motivation, Explanation, The Stanford Encyclopedia of Philosophy (Winter 2016 Edition), Edward N. Zalta (ed.), URL = <https://plato.stanford.edu/archives/win2016/entries/reasons-just-vs-expl/>.

ARPALY, N., SCHROEDER, T., In Praise of Desire, New York: Oxford University Press, 2014.

AUDI, R. Practical reasoning, London: Routledge, 1989.

BARAQUIN, N., BAUDART, A., DUGUÉ, J., LAFFITTE, J., RIBES, F., e WILFERT, J. Dictionnaire de Phlosophie. Armand Colin. 4a edição: (2011 [1995]).

HAIDT, J., The emotional dog and its rational tail: A social intuitionist approach to moral judgment. Psychological Review. 108, 814-834. (2000; [2001]).

HARMAN, G., MASON, K., e SINNOTT-ARMSTRONG, W., Moral Reasoning, In: DORIS, J.M., The Moral Psychology Handbook, 2009. pp. 205-244. 
HUME, D., Tratado da Natureza humana. 2.ed. revista e ampliada, São Paulo: Unesp, 2009 [trad. de Débora Danowsk

MARGOLIS, E., LAURENCE, S. Concepts. The Stanford Encyclopedia of Philosophy, 2014, Edward N. Zalta (ed.), Disponível em: URL = <https://plato.stanford.edu/archives/spr2014/entries/concepts/>. Acesso em: 20 jan. 2017.

PEQUENO, M., A Moral e as Emoções. Curitiba: Editora CRV, 2017.

PRINZ, J. Gut Reactions: a Perceptual Theory of Emotion, Oxford: Oxford University Press. 2004.

RICHARDSON, H. S. Moral Reasoning, The Stanford Encyclopedia of Philosophy (Spring 2013 Edition), ZALTA, E. N (ed.) URL = <http://plato.stanford.edu/archives/spr2013/entries/reasoning-moral/>. Acesso em: 02 jan. 2017.

ROSATI, C. S., Moral Motivation, The Stanford Encyclopedia of Philosophy (Winter 2016 Edition), Edward N. Zalta (ed.), URL = $<$ https://plato.stanford.edu/archives/win2016/entries/moral-motivation/>.

ROSS, Sir David. Prima Facie Duties. In: GOWANS, Christopher. Moral Dilemmas. New York: 1987, pp. 83-100.

VÄYRYNEN, P. Reasons and Moral Principles, Forthcoming In Oxford Handbook of Reasons and Normativity, ed. Daniel Star (Oxford University Press). Disponível em: https://philpapers.org/archive/VAYRAM.pdf. Acesso em 21 jun. 2017. 